\title{
Baseline Test Specimen Machining Report
}

\author{
Mark Carroll
}

August 2009
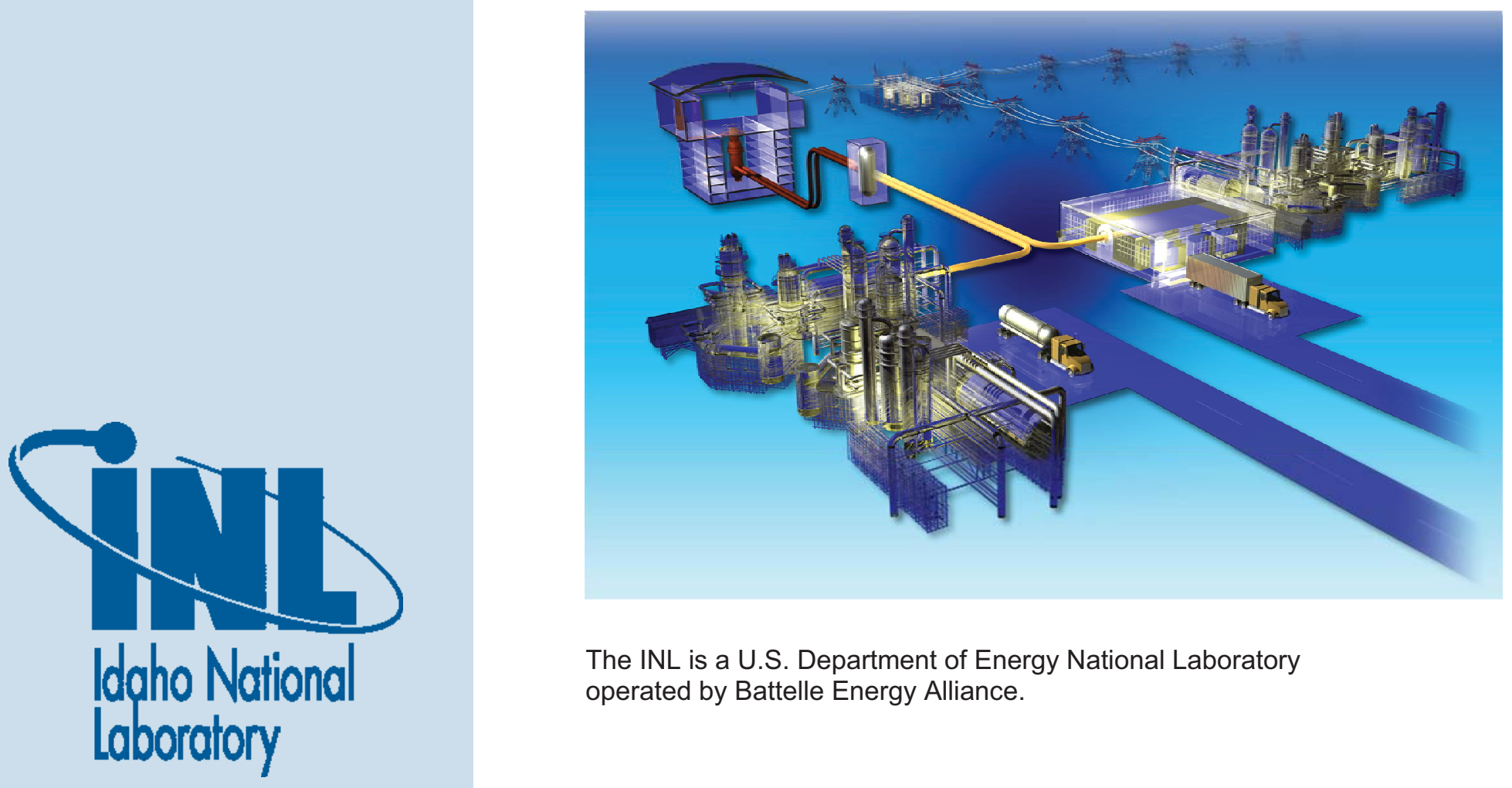

The INL is a U.S. Department of Energy National Laboratory operated by Battelle Energy Alliance. 


\section{DISCLAIMER}

This information was prepared as an account of work sponsored by an agency of the U.S. Government. Neither the U.S. Government nor any agency thereof, nor any of their employees, makes any warranty, expressed or implied, or assumes any legal liability or responsibility for the accuracy, completeness, or usefulness, of any information, apparatus, product, or process disclosed, or represents that its use would not infringe privately owned rights. References herein to any specific commercial product, process, or service by trade name, trade mark, manufacturer, or otherwise, does not necessarily constitute or imply its endorsement, recommendation, or favoring by the U.S. Government or any agency thereof. The views and opinions of authors expressed herein do not necessarily state or reflect those of the U.S. Government or any agency thereof. 
INL/EXT-09-16709

\title{
Baseline Test Specimen Machining Report
}

\author{
Mark Carroll
}

August 2009

Idaho National Laboratory

Next Generation Nuclear Plant Project

Idaho Falls, Idaho 83415

Prepared for the

U.S. Department of Energy

Office of Nuclear Energy

Under DOE Idaho Operations Office

Contract DE-AC07-05ID14517 



\section{Next Generation Nuclear Plant Project}

\section{Baseline Test Specimen Machining Report}

INL/EXT-09-16709

August 2009

Approved by:

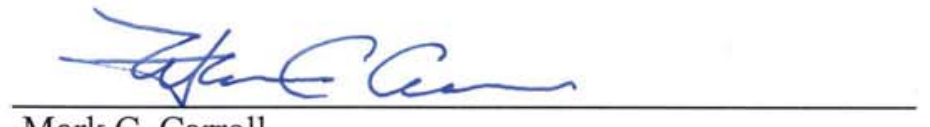

Mark C. Carroll

NGNP Staff Scientist

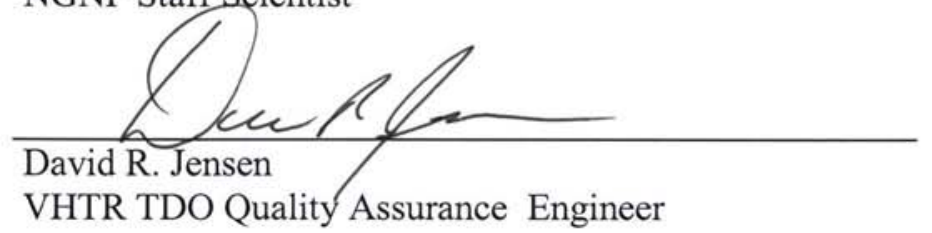

Arane V Cor

Diane V. Croson

VHTR TDO Project Manager

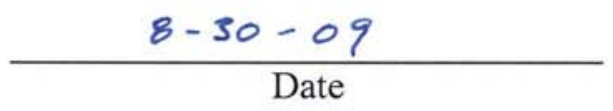

$\frac{8 / 30 / 09}{\text { Date }}$

$8 / 30 / 09$ 



\section{SUMMARY}

The Next Generation Nuclear Plant (NGNP) Project is tasked with selecting a high temperature gas reactor technology that will be capable of generating electricity and supplying large amounts of process heat. The NGNP is presently being designed as a helium-cooled high temperature gas reactor (HTGR) with a large graphite core. The graphite baseline characterization project is conducting the research and development (R\&D) activities deemed necessary to fully qualify nuclear-grade graphite for use in the NGNP reactor. One of the major fundamental objectives of the project is establishing nonirradiated thermomechanical and thermophysical properties by characterizing lot-to-lot and billet-to-billet variations (for probabilistic baseline data needs) through extensive data collection and statistical analysis.

The reactor core will be made up of stacks of graphite moderator blocks. In order to gain a more comprehensive understanding of the varying characteristics in a wide range of suitable graphites, any of which can be classified as "nuclear grade," an experimental program has been initiated to develop an extensive database of the baseline characteristics of numerous candidate graphites.

Various factors known to affect the properties of graphite will be investigated, including specimen size, spatial location within a graphite billet, specimen orientation within a billet (either parallel to $[\mathrm{P}]$ or transverse to $[\mathrm{T}]$ the long axis of the as-produced billet), and billet-to-billet variations within a lot or across different production lots. Because each data point is based on a certain position within a given billet of graphite, particular attention must be paid to the traceability of each specimen and its spatial location and orientation within each billet.

The evaluation of these properties is discussed in the Graphite Technology Development Plan (Windes et. al 2007). One of the key components in the evaluation of these graphite types will be mechanical testing of specimens drawn from carefully controlled sections of each billet. To this end, this report discusses the machining of the first set of test specimens that will be evaluated in this program through tensile, compressive, and flexural testing. Validation that the test specimens have been produced to the tolerances required by the applicable American Society for Testing and Materials (ASTM) standards and quality control levels required by this program will demonstrate the viability of sending graphite to selected suppliers that will provide valuable and certifiable data to future data sets that are integral to the NGNP program and beyond. 


\section{CONTENTS}

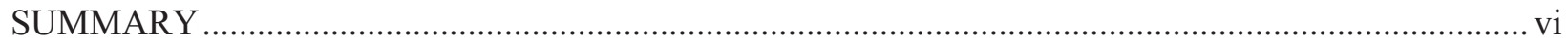

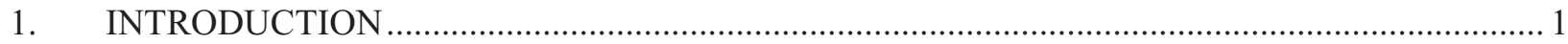

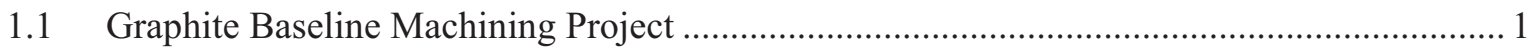

2. Initial Baseline Graphite Characterization Machining …........................................................ 1

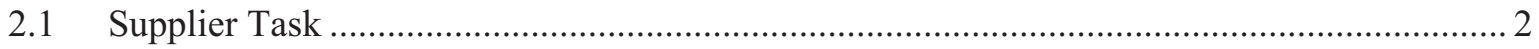

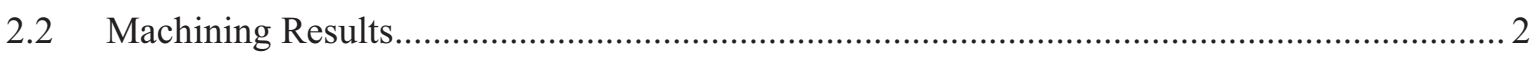

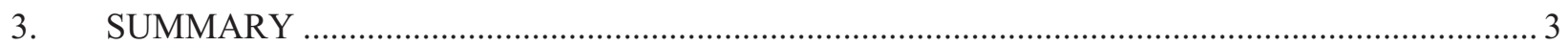

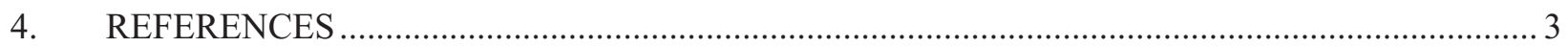

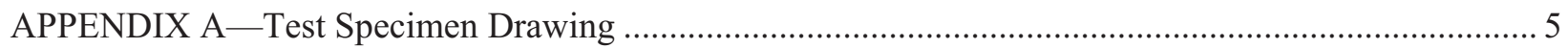

\section{FIGURES}

Figure 1. A 2,250 lb billet of NBG-18 graphite slated for sectioning and machining into

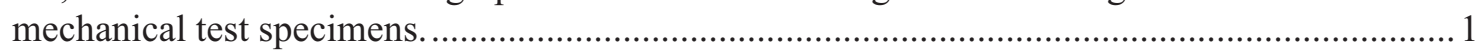

Figure 2. Full-size billet 635-14 sectioned into slabs and quartered per drawing 759142 (inset). The figure shows actual sub-blocks from Slab 1

\section{TABLES}

Table 1. Graphite sample data table showing 100\% verification of critical measurements for each of the sample types. 


\section{Baseline Test Specimen Machining Report \\ 1. INTRODUCTION}

Characterizing the baseline properties of nuclear-grade graphite will require an extensive amount of mechanical testing from carefully controlled sections of as-produced graphite billets. The handling, traceability, and machining of these billets into test specimens per American Society for Testing and Materials (ASTM) standards requires standards of quality control that limit the number of available suppliers of machining services. This report describes the results of the initial machining effort for the production of mechanical test specimens for tensile, flexural, and compressive testing. As illustrated in Figure 1, the relative size of the test specimens being machined from the billets will require numerous presectioning steps before the final machining operations can be performed.

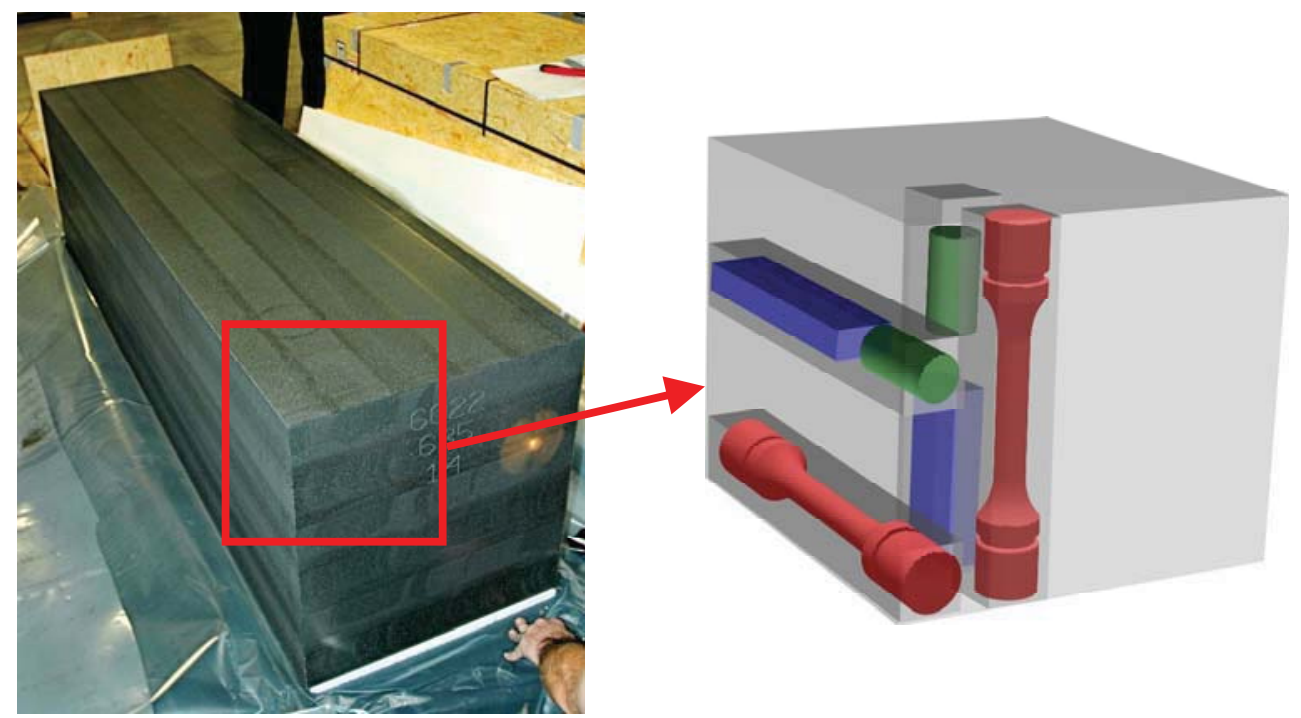

Figure 1. A 2,250 lb billet of NBG-18 graphite slated for sectioning and machining into mechanical test specimens.

\subsection{Graphite Baseline Machining Project}

Machining of test specimens for the Baseline Characterization program will depend on the following objectives:

1. Selecting suppliers of machining services that are equipped to handle graphite.

2. Establishing the requisite shop-level quality requirements needed to ensure that specimen production remains at Quality Level 2 (QL-2).

3. Shipping presectioned graphite to select suppliers for final sectioning and machining of graphite test specimens that are ready to be evaluated to applicable ASTM standards.

To meet these objectives, the selected supplier/suppliers were contracted to machine test samples in accordance with Idaho National Laboratory Statement of Work (SOW)-7227 (2009). This statement of work describes in detail both the required machining task and the requisite quality program that would have to be implemented by the contracted supplier in order to provide approved test specimens for the Next Generation Nuclear Plant (NGNP) Baseline Graphite Characterization program. 


\section{Initial Baseline Graphite Characterization Machining}

The initial machining task for the baseline Graphite Characterization program was carried out by General Products Machine Shop (GPMS) in Pocatello, ID. GPMS was added to the Approved Supplier List as a QL-2 supplier through an onsite (Level 1) audit conducted August 10-11, 2009.

\subsection{Supplier Task}

Figure 2 shows an example of the sub-blocks sent out for machining. The first machining task for GPMS was to section and extract test samples from sub-blocks 5C and 5D per partial fulfillment of Contract Requisition \#279691. Sub-blocks will generally be sent out in limited numbers (likely two subblocks from single slabs per shipment) to provide additional sample control with respect to specimen traceability.

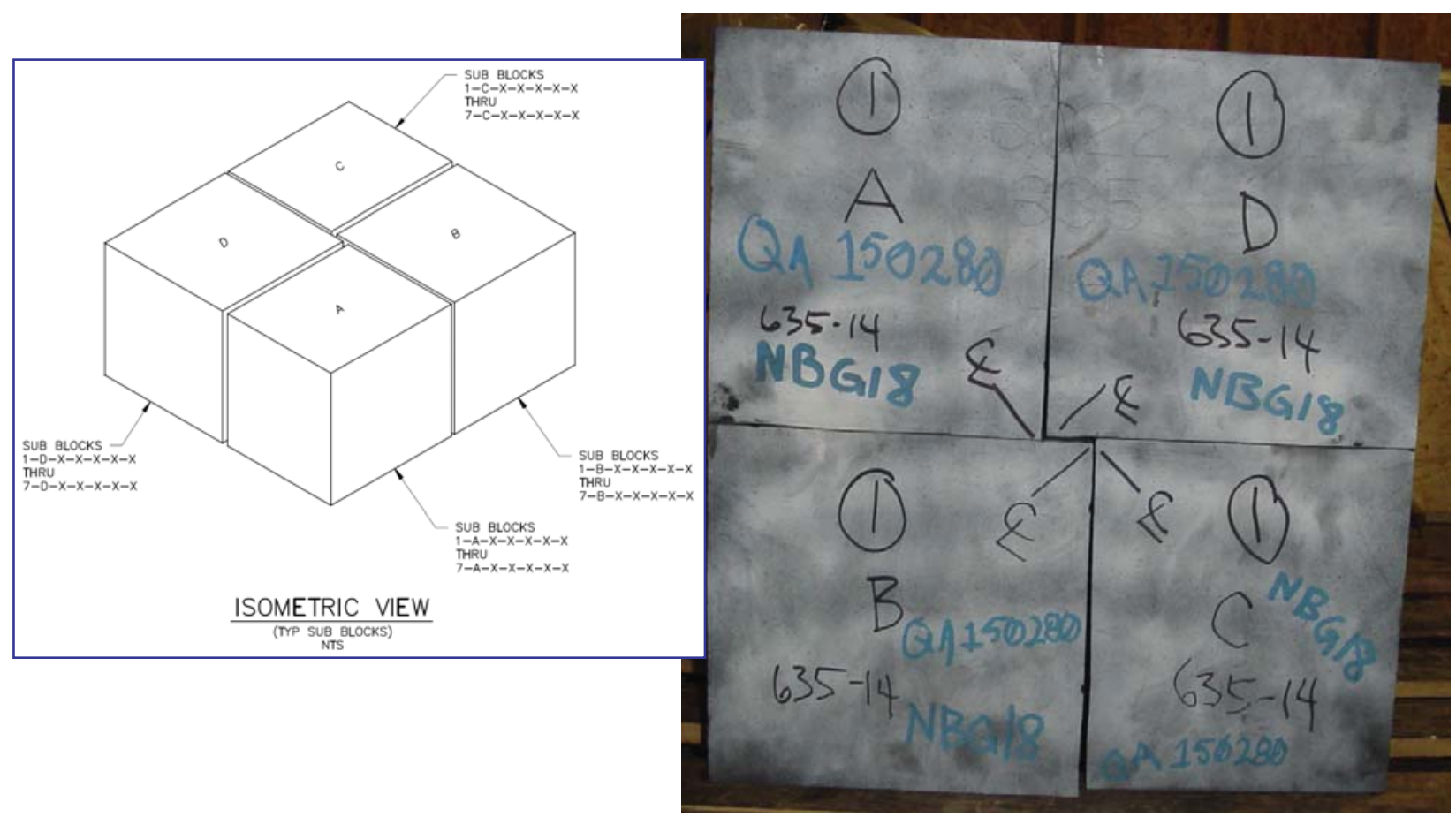

Figure 2. Full-size billet 635-14 sectioned into slabs and quartered per drawing 759142 (inset). The figure shows actual sub-blocks from Slab 1.

\subsection{Machining Results}

Table 1 shows the measured values for machined test specimens per ASTM C 749 (Tensile), ASTM C 695 (Compressive), and ASTM C 651 (Flexural) testing of graphite material. Specimens were machined to these standards as illustrated in INL Drawing 759292 "NBG-18 Billet 1A," Sheet 5 (see Appendix A).

The specimens shown in Table 1 meet the requisite measured tolerances for testing per the applicable ASTM standards and the Baseline Graphite Characterization Plan (2009). 
Table 1. Graphite sample data table showing 100\% verification of critical measurements for each of the sample types. (QA-stamped Final Inspection sheets kept on file at GPMS).

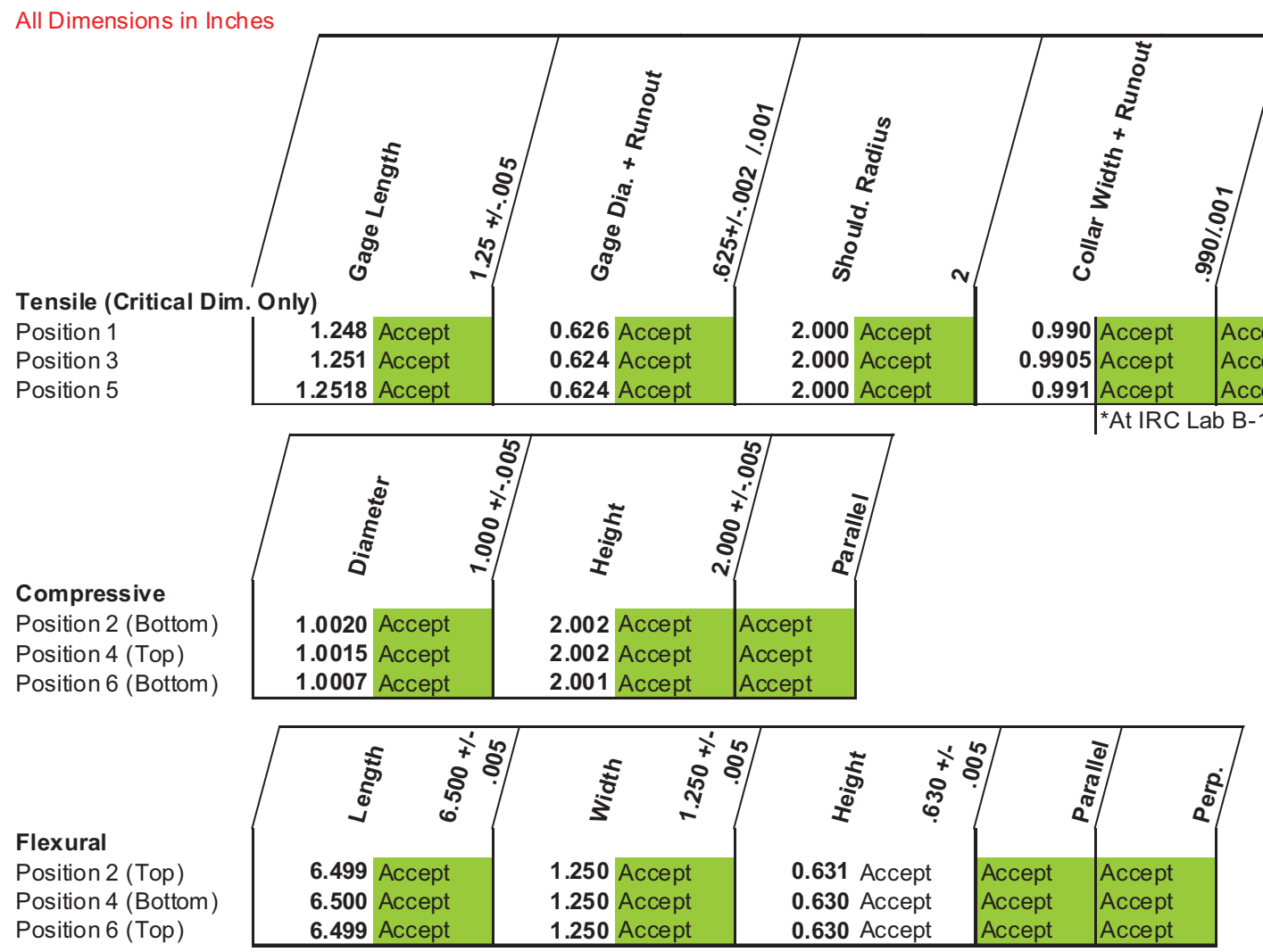

Test specimens were extracted from sub-slab 5C, row 4, positions 1-6, which per sheet 2 of Drawing 759292 yields three tensile, three compressive, and three flexural specimens. The BEA Technical Representative was on hand for the dimensional verification at GPMS. For the tensile specimens, a final dimensional verification was made when the samples were returned to the INL Research Center for the fitment of the tensile shoulder sections in the split-collar test grips per ASTM C 749.

\section{SUMMARY}

The initial machining portion is a small fraction in the overall Baseline Graphite Characterization program that is expected to evaluate thousands of test samples from numerous graphite grades and lots. Still, it is a significant milestone to have the first of many machined test specimens completed because the viability of both the machining program and quality control program have been demonstrated.

The successful machining of the first set of test specimens that will contribute to the comprehensive baseline data set is proof of the capabilities of one of the selected suppliers that will be tasked with this work. Future machining tasks will have slightly differing scope from billet to billet and grade to grade, but will follow the same machining, cleanliness, traceability, and overall quality requirements established during this initial machining task. 


\section{REFERENCES}

Windes, W. E., T. D. Burchell and R. Bratton, 2007, Graphite Technology Development Plan, INL/EXT07-13165, Idaho National Laboratory, Idaho Falls, ID, 35 p.

SOW-7227, 2009, "Machining Graphite for Baseline Characterization: NBG+-18 Billet 1A" Rev. 1, Idaho National Laboratory, Idaho Falls, ID, August 4, 2009, 12 p.

Baseline Graphite Characterization Plan: Electromechanical Testing (in review), Idaho National Laboratory, Idaho Falls, ID, 2009.

ASTM C 749-08, "Standard Method for Tensile Stress-Strain of Carbon and Graphite", ASTM International, West Conshohocken, PA, 2008, 12 p.

ASTM C 695-91, "Standard Method for Compressive Strength of Carbon and Graphite", ASTM International, West Conshohocken, PA, Re-Approved 2005, 3 p.

ASTM C 651-91, "Standard Method for Flexural Strength of Manufactured Carbon and Graphite Articles Using Four-Point Loading at Room Temperature", ASTM International, West Conshohocken, PA, Re-Approved 2005, 3 p. 


\section{APPENDIX A}

\section{Test Specimen Drawing}




\section{Appendix A Sheet 5 from INL Drawing 759292 \\ (not to scale)}

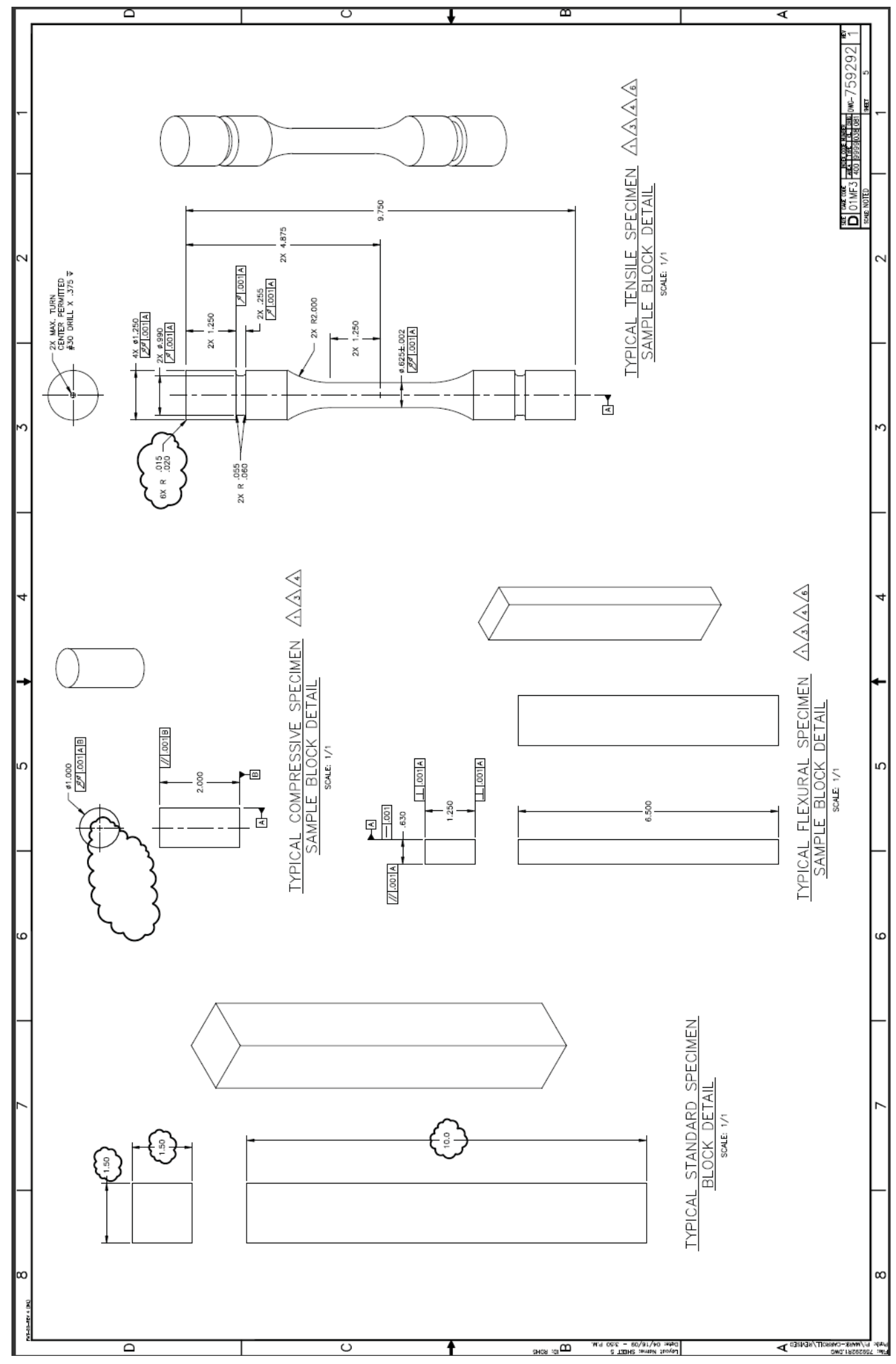

